\title{
Enhanced Basal and Disorderly Growth Hormone Secretion Distinguish Acromegalic from Normal Pulsatile Growth Hormone Release
}

\author{
Mark L. Hartman, ${ }^{\star}$ Steven M. Pincus, ${ }^{*}$ Michael L. Johnson, ${ }^{5}$ D. Hunter Matthews, ${ }^{*}$ Lindsay M. Faunt, ${ }^{5}$ Mary Lee Vance, \\ Michael O. Thomer, ${ }^{*}$ and Johannes D. Veldhuis* \\ Departments of *Medicine and ${ }^{\S}$ Pharmacology, University of Virginia Health Sciences Center and National Science Foundation Center \\ for Biological Timing, Charlottesville, Virginia 22908
}

\begin{abstract}
Pulses of growth hormone (GH) release in acromegaly may arise from hypothalamic regulation or from random events intrinsic to adenomatous tissue. To distinguish between these possibilities, serum GH concentrations were measured at 5-min intervals for $\mathbf{2 4} \mathrm{h}$ in acromegalic men and women with active $(n=19)$ and inactive $(n=9)$ disease and in normal young adults in the fed $(n=20)$ and fasted $(n=16)$ states. Daily GH secretion rates, calculated by deconvolution analysis, were greater in patients with active acromegaly than in fed $(P<0.05)$ but not fasted normal subjects. Significant basal (nonpulsatile) GH secretion was present in virtually all active acromegalics but not those in remission or in fed and fasted normal subjects. A recently introduced scale-and model-independent statistic, approximate entropy (ApEn), was used to test for regularity (orderliness) in the GH data. All but one acromegalic had ApEn values greater than the absolute range in normal subjects, indicating reduced orderliness of GH release; ApEn distinguished acromegalic from normal GH secretion (fed, $P<10^{-12}$; fasted, $P<10^{-7}$ ) with high sensitivity (95\%) and specificity (100\%). Acromegalics in remission had ApEn scores larger than those of normal subjects $(P<\mathbf{0 . 0 0 0 1})$ but smaller than those of active acromegalics $(P<0.001)$. The coefficient of variation of successive incremental changes in GH concentrations was significantly lower in acromegalics than in normal subjects $(P<0.001)$. Fourier analysis in acromegalics revealed reduced fractional amplitudes compared to normal subjects $(P<0.05)$. We conclude that GH secretion in acromegaly is highly irregular with disorderly release accompanying significant basal secretion. (J. Clin. Invest. 1994. 94:1277-
\end{abstract}

This work was presented in part at the Third International Pituitary Congress, Marina Del Ray, California, June 13-15, 1993.

Address correspondence to Dr. Mark L. Hartman, Department of Medicine, Box 511, University of Virginia Health Sciences Center, Charlottesville, VA 22908.

Received for publication 6 January 1994 and in revised form 31 May 1994.

1. Abbreviations used in this paper: ApEn, approximate entropy; CV, coefficient of variation; CV $\left(\left|\Delta X_{i}\right|\right)$, coefficient of variation of incremental change; GH, growth hormone; GHRH, GH releasing hormone; $G_{s}$, stimulatory $G$ protein; IRMA, immunoradiometric assay; $L_{v}$, liter of distribution volume; $\mathrm{Z}$ score, standard deviate score; $\alpha$, distribution phase of GH disappearance; $\beta$, elimination phase of GH disappearance.

The Journal of Clinical Investigation, Inc.

- Volume 94, September 1994, 1277-1288
1288.) Key words: acromegaly • pituitary neoplasms • somatotropin • algorithms $\bullet$ periodicity

\section{Introduction}

We and others have reported that increased pulse frequency and interpulse concentrations characterize growth hormone $(\mathrm{GH})^{1}$ release in acromegaly as determined by several objective pulsedetection algorithms $(1,2)$. However, little is known about the nature of the secretory events at the level of the anterior pituitary gland that give rise to these changes in serum GH concentrations. Secretion cannot be inferred readily from the serum GH concentrations, because of the confounding influence of ongoing metabolic clearance, which has been reported to be normal $(3-6)$, increased $(7,8)$ or decreased $(6,9,10)$ in acromegaly. Furthermore, whether episodes of GH secretion arise from normal hypothalamic regulation or from random events intrinsic to adenomatous tissue is unknown. Pulsatile GH release persists during continuous infusions of $\mathrm{GH}$ releasing hormone (GHRH) (11), octreotide (a long-acting somatostatin analogue) treatment $(12,13)$, during pregnancy when insulin-like growth factor-I (IGF-I) levels are increased (14), and during fasting when IGFI levels are decreased (15). These observations have been interpreted by some groups as evidence that hypothalamic regulation of GH secretion persists in acromegaly, with perhaps decreased negative feedback by IGF-I $(11,12,14,15)$. However, high frequency pulsatile release of $\mathrm{GH}$ has also been observed in vitro from perifused primate hemipituitaries (16). Thus, episodic GH release in vivo by somatotroph adenomas may also reflect secretory events that are independent of hypothalamic regulation.

We hypothesized that GH secretion in acromegaly is primarily autonomous with irregular secretory activity superimposed upon enhanced basal secretion. In contrast, normal GH secretion is characterized by minimal basal secretion and highly regulated pulses of GH secretion. To evaluate these hypotheses, we used several recently developed analytical and mathematical methods to compare objectively acromegalic and normal episodic $\mathrm{GH}$ secretion. To evaluate basal secretion we used high, intermediate, and low literature values of the $\mathrm{GH} t_{1 / 2}$ in conjunction with a waveform-independent deconvolution method that requires no assumptions about the nature or time-course of underlying hormone secretory events (17). Regularity in the GH concentration-time series was quantified with a recently introduced statistic termed approximate entropy (ApEn), which calculates the logarithmic likelihood that patterns that are similar remain similar on the next incremental comparison (18). ApEn is a modelindependent (no assumptions about periodicity or waveforms) and scale-independent (unaffected by differences in mean values) statistic, which has been shown to discern differences in 
underlying episodic behavior that may not be detected by pulse detection algorithms (19). The presence of underlying periodic rhythms was also assessed by classical Fourier time series analysis (20). Physiologically enhanced (e.g., by fasting) GH secretion in normal subjects was compared with that of acromegalic patients to test the possibility that observed differences between normal and acromegalic $\mathrm{GH}$ release were the result of undetectable GH concentrations throughout much of the day in fed normal subjects $(21,22)$. We report that episodic $\mathrm{GH}$ release in acromegaly can be distinguished objectively from physiological GH secretion by: ( $a$ ) enhanced basal (interpulse) GH secretion; (b) increased irregularity (disorderliness) in the patterns of $\mathbf{~ G H}$ release; and $(c)$ a relative damping of underlying periodic rhythms.

\section{Methods}

Subjects and study design. The studies were approved by the Human Investigation and General Clinical Research Center Advisory Committees of the University of Virginia. All patients and normal volunteers gave written informed consent. 19 patients with active acromegaly ( 9 men, 10 women; ages 24-64) were studied; five patients had previously been treated with transsphenoidal surgery and/or radiation therapy but had residual active disease. Previous medical treatments included bromocriptine in four patients (discontinued 2-6 wk before study) and octreotide in two patients (discontinued 4-18 mo before study). The diagnosis was based on the failure of serum $\mathrm{GH}$ concentrations to decrease to $<1 \mu \mathrm{g} / 1$ after ingestion of $100 \mathrm{~g}$ glucose and an elevated serum IGF-I concentration. Nine acromegalic patients (three men, six women; ages 29-69) were studied during biochemical remission defined by a post-oral glucose $\mathrm{GH}$ nadir of $<1 \mu \mathrm{g} /$; eight patients had been treated with transsphenoidal surgery and/or radiation therapy and one received bromocriptine therapy. All nine patients considered to be in remission had serum IGF-I concentrations within the normal range of young adults. Two of these patients had serum IGF-I levels which were slightly higher than expected for older adults $(1,23)$. All acromegalics had normal biochemical indices of renal, hepatic, and hematologic function. A detailed endocrine evaluation was performed on all subjects including fasting serum concentrations of glucose, IGF-I, thyroxine, triiodothyronine resin uptake, thyroid stimulating hormone, cortisol, prolactin, luteinizing hormone, follicle stimulating hormone, and testosterone (men only). All acromegalic patients had either normal thyroid and adrenal function or were receiving appropriate hormone replacement therapy. Five patients were taking L-thyroxine and two received glucocorticoid replacement. One man was hypogonadal at the time of the study; a second man received testosterone replacement therapy. Two postmenopausal acromegalic women discontinued estrogen and progesterone therapy 1-8 wk before the study. Three acromegalic patients were taking glyburide treatment for diabetes mellitus. Antihypertensive medications were withheld during the period of blood sampling. One acromegalic man was studied 8 wk after radioactive iodine therapy for hyperthyroidism; he was euthyroid at the time of the study. The serum GH concentrations from 13 acromegalic patients, 5 acromegalics in remission and the normal volunteers (in the fed state) have previously been reported (1), but the analyses presented here are new.

20 healthy normal volunteers, 12 men (ages 22-28) and 8 women in the early follicular phase of the menstrual cycle, (ages 23-25) served as controls. All normal subjects were within $15 \%$ of ideal body weight, were non-smokers, were taking no medications, had normal sexual function, had not undertaken any transmeridian travel for at least $4 \mathrm{wk}$, and had a normal physical examination; the women had regular menstrual cycles. All normal subjects had normal biochemical indices of renal, hepatic, and hematologic function, and had normal endocrine evaluations.

The acromegalic patients and normal volunteers were admitted to the General Clinical Research Center the evening before study. At 0700 $\mathrm{h}$ an indwelling venous cannula was inserted into a forearm vein and blood samples for measurement of GH levels were obtained at 5-min intervals from $0800-0800 \mathrm{~h}$. Meals were served at 0900,1300 and 1800 $\mathrm{h}$ and water was allowed ad libitum. Patients were requested not to smoke but two acromegalic patients did not comply. Subjects were permitted to ambulate on the ward and daytime naps were prohibited. Sleep was encouraged after $2200 \mathrm{~h}$ and the nursing staff recorded all periods of sleep.

To compare physiologically increased GH secretion with acromegaly, 16 normal subjects ( 10 men, 6 women) were also studied after fasting for $5 \mathrm{~d}$, which is known to increase GH secretion (24). During the fast, subjects ingested only water, potassium chloride $(20 \mathrm{meq} / \mathrm{d})$, and a multivitamin tablet. Compliance with the fast was monitored by daily weights and measurement of urine ketones. Daily blood samples $(0800 \mathrm{~h})$ were obtained for complete blood counts, serum chemistries, and hepatic enzymes to monitor possible adverse effects of the fast.

Assays. Serum GH concentrations were measured in duplicate by immunoradiometric assay (IRMA) (Nichols Institute, San Juan Capistrano, CA) using standards diluted in either equine or human serum. As previously described, results obtained from assays in which equine serum was used were multiplied by a factor of 0.5 to correct for the parallel shift in the IRMA standard curve caused by equine serum matrix relative to results obtained with human serum $(1,21,22,25)$. The sensitivity of the assay was $0.2 \mu \mathrm{g} /$; samples with $<0.2 \mu \mathrm{g} / \mathrm{GH}$ were assigned a value of $0.2 \mu \mathrm{g} / 1$ for statistical analyses. A detailed description of the mean intraassay coefficients of variation (CV) across the full range of serum GH concentrations in acromegalics has been previously reported (1). Serum IGF-I was measured by three different methods over a 7-yr period: (a) RIA of unextracted serum in the presence of heparin to dissociate IGF-I from its binding proteins (23); (b) RIA of unextracted serum (Nichols Institute Somatomedin-C assay); or (c) RIA of serum after acid-ethanol extraction (Nichols Institute IGF-I by extraction assay). Results were compared to age-adjusted normal ranges when available (methods $a$ and $c$ ). Other hormones were measured as previously described (1).

Deconvolution analysis of $\mathrm{GH}$ secretion. We wished to determine whether enhanced basal GH secretion was present in acromegaly. However, deconvolution methods cannot readily simultaneously resolve hormone $t_{1 / 2}$ and admixed pulsatile and basal secretion rates (17). Furthermore, the GH $t_{1 / 2}$ and the time-dependent shape of underlying GH secretory events in acromegaly is unknown. To circumvent these problems, we used a waveform-independent deconvolution method, which calculates hormone secretion rates at each time point given an estimated hormone $t_{12}$ and its associated variance, without making any assumptions about the nature of underlying hormone secretory events (17). For normal subjects, a previously determined estimate of the two-component endogenous GH $t_{1 / 2}$ was used (mean \pm SEM): (a) distribution phase $(\alpha)$, $3.5 \pm 0.7 \mathrm{~min}$; (b) elimination phase $(\beta), 20.7 \pm 0.7 \mathrm{~min}$; (c) fractional amplitude of the second component, 0.63 (26). These same parameters were used to analyze the fasting data since previous studies have indicated that the GH $t_{1 / 2}$ is not altered by fasting (22). Since the GH metabolic clearance rate has been reported to be normal, increased and decreased in acromegaly, we used low $(8.9 \pm 0.39 \mathrm{~min})(27)$, normal $(20.7 \pm 0.7 \mathrm{~min})(26)$ and high $(33.1 \pm 1.7 \mathrm{~min})$ estimates of $\beta$ to calculate GH secretion rates for the acromegalic data; $\alpha$ was assumed to be $3.5 \pm 0.7 \mathrm{~min}$ for all analyses (26). The high estimate of $\beta$ was based on the data of Thompson et al. (10) who observed a metabolic clearance rate of exogenous GH which was 1.6-fold slower in acromegalics compared with normal subjects. The waveform-independent deconvolution method uses the experimental variances associated with the $t_{1 / 2}$ estimate and hormone measurements to calculate statistical confidence intervals for the secretion rate value at each time point. A standard deviate (Z) score (ratio of secretion estimate to the SD) may then be calculated for each calculated secretion rate, as well as its first derivative. This enables one to determine whether secretion is significantly nonzero in individual samples and whether significant increases or decreases (defined by the 
first derivative) in the secretion rates have occurred. Distinct peaks in the calculated sample secretion profiles were defined by: $(a)$ a significant (nonzero) value ( $\mathrm{Z}$ score $>1.645, P<0.05$ ); and $(b)$ a significant first derivative $(\mathrm{Z}$ score $>3.5)$. Nadirs were defined as all regions (sample secretory values) between significant secretory peaks (17). The more stringent $\mathrm{Z}$ score (3.5) to define significant first derivatives was chosen to constrain the false positive peak detection rate to $<5 \%$, based on preliminary validation studies using simulated $\mathrm{GH}$ pulse series generated by a multiple parameter convolution integral model (28). This analysis indicated that false positive peaks were detected more frequently in data with elevated baselines, as occurs with acromegalic data. Basal (nonpulsatile) GH secretion was defined to be present when mean lowest interpulse (nadir) secretion rates were significantly greater than zero (Z score $>1.645, P<0.05$ ). Calculated GH secretion rates and their statistical confidence intervals are expressed as $\mu \mathrm{g} \mathrm{GH}$ secreted per liter of distribution volume $\left(\mathrm{L}_{\mathrm{v}}\right)$ per $\min \left(\mu \mathrm{g} \cdot \mathrm{L}_{\mathrm{v}}{ }^{-1} \cdot \min ^{-1}\right)$. Daily $(24-\mathrm{h}) \mathrm{GH}$ production rates were estimated by multiplying the mean $\mathrm{GH}$ secretion rate by $1440 \mathrm{~min}$.

Approximate entropy statistic (ApEn). ApEn is a model-independent statistic for assessing regularity of time-series data (18). It assigns a single nonnegative number to a time series with larger values corresponding to greater apparent process randomness. ApEn measures the logarithmic likelihood that runs of patterns that are similar remain similar on next incremental comparisons. The calculation of ApEn is given in Appendix A. Two input parameters, $m$ and $r$, must be fixed to compute ApEn. For this study, we calculated two sets of ApEn values for each data set: $(a) m=1, r=20 \%$ of the average SD of the GH time-series; (b) $m=2$, and $r=20 \%$ of the average SD of the GH time-series. Previous studies that included both theoretical analysis and clinical applications have demonstrated that these input parameters will produce good statistical validity for ApEn for time series of upwards of 100 data points $(18,19,29-31)$.

ApEn has been demonstrated to be very stable to small changes in noise characteristics, and infrequent and significant data artifacts. It accounts for a variety of dominant and subordinate patterns in data; notably, it will detect (be affected by) changes in underlying episodic behavior that are not reflected in changes in peak occurrences or amplitudes (19). Additionally, ApEn provides a direct barometer of feedback system change in many coupled systems.

In choosing the $r$ input parameter in ApEn as a fixed percentage of each data set's SD, we normalize each epoch by its overall SD. We call this normalized regularity (30). We thus decorrelate the SD and the present quantification of regularity, ApEn, in that ApEn as specified above is scale invariant - constant signal scale enlargement would produce the identical ApEn value to the base signal ApEn value.

Finally, ApEn is a relative, not absolute measure of process regularity, and can show significant variation with changing $m$ or $r$ input parameters, and changing noise characteristics $(18,19,29,31)$. Since ApEn will generally increase with increasing process noise (and increasing intra-assay variation), it is important to compare data sets with similar assay CVs, as we do here.

Coefficient of variation of incremental change $\left[C V\left(\left|\Delta X_{i}\right|\right)\right]$. In a time-series of data $X_{1}, X_{2}, \ldots X_{n}$, the incremental change $\Delta X_{i}$, defined as $X_{i+1}-X_{i}$, is a standard quantification of short-term variation. We study the coefficient of variation (SD/mean) of all the $\left|\Delta X_{i}\right|$ in a data set as an index of the constancy of incremental change in the time series. Data with a relatively steady rate of change will have a small CV $\left(\left|\Delta X_{i}\right|\right)$ whereas data with much of the overall statistical variation occurring in brief bursts will have a large $C V\left(\left|\Delta X_{i}\right|\right)$. Since superimposed noise tends to be relatively constant in magnitude, a large CV $\left(\left|\Delta \mathbf{X}_{\mathrm{i}}\right|\right)$ would rarely be due to noise alone, and would typically rather appear to mark abrupt input/output changes, as opposed to steady flow. We calculated CV $\left(\left|\Delta \mathrm{X}_{\mathrm{i}}\right|\right)$ to test the hypothesis that GH secretion in acromegaly has a more nearly constant incremental change over time compared to normal GH secretion, which is characterized by more prominent and distinct bursts of secretory activity. $\operatorname{CV}\left(\left|\Delta X_{i}\right|\right)$ is scale invariant in the sense stated above, so this comparison is not affected by the differences in mean $\mathrm{GH}$ concentrations between acromegalic and normal subjects.

Fourier series analysis. Normal GH secretion is characterized by a nyctohemeral rhythm (GH concentrations highest at night) and higher frequency ultradian rhythms. To test the hypothesis that underlying periodicity in GH secretion is damped in acromegaly, each GH concentration-time series was analyzed as a Fourier expansion, which yielded a function that traverses all the data points as an exact linear composite of distinct sine and cosine functions with $(n-1) / 2$ periodicities. The Fourier analysis was truncated to exclude very high-order terms that correspond to experimental noise (20). This optimal order of fit (e.g., number of harmonics) was determined by two independent statistical methods: (a) the runs test for randomness of residuals (32); and (b) the Akaike information content to monitor overparameterization (33). Significant terms correspond to underlying periodic rhythms. The ratio of the highest Fourier amplitude to the zero order constant (weighted mean serum GH concentration) was calculated as an index of the contribution of underlying periodic rhythms to the observed serum GH concentrations.

Statistical analysis. Results for acromegalic patients were compared to fed and fasted normal subjects by gender using analysis of variance with Dunnett's test for multiple comparisons or unpaired two-sided Student's $t$ tests. Nonnormally distributed data were log transformed prior to analysis. Statistical significance was assumed for $P<0.05$. Results are expressed as mean \pm SEM except where noted.

\section{Results}

24-h profiles of serum GH concentrations and GH secretion rates. Fig. 1 depicts serum $\mathrm{GH}$ concentrations measured in blood obtained at 5-min intervals for $24 \mathrm{~h}$ from two patients with active acromegaly and two patients with acromegaly in biochemical remission after transsphenoidal surgery. Fig. 2 illustrates 24-h GH profiles from two normal subjects in the fed state and on the fifth day of a water-only fast to enhance $\mathrm{GH}$ secretion physiologically. In Fig. 3, GH sample secretion rates corresponding to the males shown in Fig. 1 and 2 are shown. Visual inspection of these typical profiles suggests that in normal subjects GH secretion occurs in distinct bursts with intervening periods of relative secretory quiescence. With fasting, serum GH concentrations become continuously elevated but the pattern of prominent bursts of secretory activity with interpeak nadir secretion rates approaching zero is maintained. In acromegaly, GH concentrations are also continuously elevated but the bursts of $\mathrm{GH}$ release appear to be less prominent in comparison with the elevated baseline. As shown in Fig. 3, the distribution of sample GH secretion rates is markedly different in acromegaly. In physiological GH secretion, the distribution is skewed with the modal value near zero (corresponding to the assay sensitivity). In contrast, in acromegaly the distribution of secretion rates is more nearly symmetric with the mode significantly above zero, corresponding to the increased baseline. After successful transsphenoidal surgery the 24-h profiles resemble those of normal subjects with baseline GH concentrations frequently approaching assay sensitivity.

Estimates of 24-h GH production rates. Fig. 4 illustrates the 24-h GH production rates estimated by a waveform-independent deconvolution algorithm for the four groups of patients: (a) acromegalic patients with active disease; $(b)$ acromegalic patients in biochemical remission; $(c)$ normal subjects in the fed state; and $(d)$ normal subjects on day 5 of a fast (enhanced $\mathrm{GH}$ secretion). As described above, estimates of 24-h GH production rates for the acromegalic patients were derived using low, 

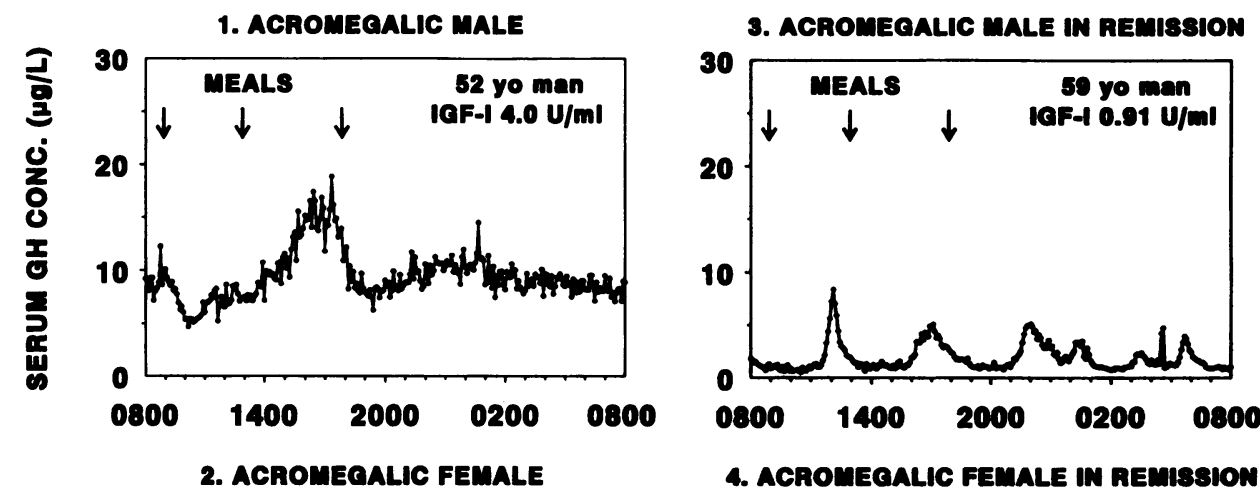

4. ACROMEQALIC FEMALE IN REMHssion

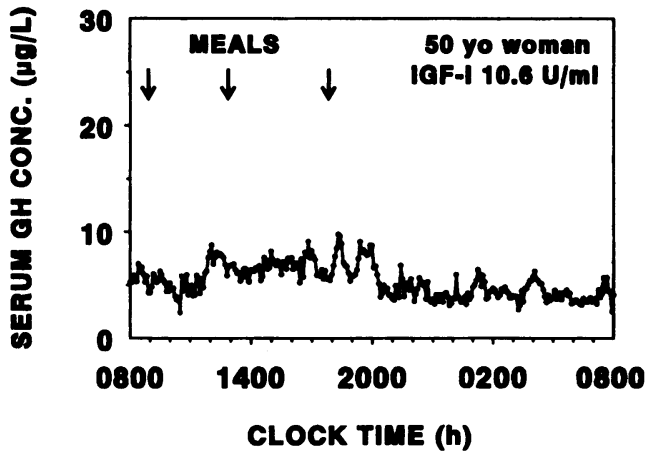

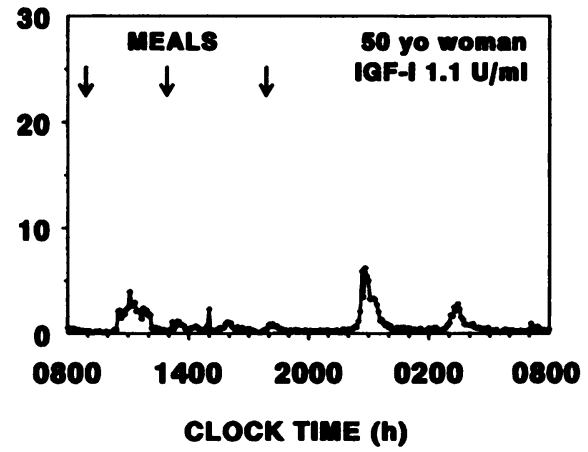

Figure 1. Serum GH concentrations measured by a two-site GH IRMA in blood obtained at 5-min intervals for $24 \mathrm{~h}$ from two patients with active acromegaly and two patients with acromegaly in biochemical remission after successful transsphenoidal surgery.

The same woman is shown before and after surgery. For panels 1 through 4, respectively, the following results were obtained (see Figs. 4-7): 24-h GH production rate $\left(t_{1 / 2}=20.7 \mathrm{~min}\right)$ $579,331,117,45 \mu \mathrm{g} \cdot \mathrm{Lv}^{-1} \cdot 24 \mathrm{~h}^{-1}$; Z-score for basal secretion rates $\left(t_{1 / 2}\right.$ $=20.7 \mathrm{~min}$ ): $2.37,1.68,1.08,0.49$; ApEn $(m=2): 1.007,1.060,0.660$, 0.509; CV $\left(\left|\Delta \mathrm{X}_{\mathrm{i}}\right|\right): 0.935,0.879$, 1.281, 1.784; ratio of highest Fourier amplitude to zero constant: $0.18,0.20$, $0.34,0.55$. intermediate and high estimates of the GH elimination $t_{1 / 2}(\beta)$, since uniform literature values for $\beta$ in acromegaly are not available $(10,26,27)$; for the normal subjects the intermediate value of $\beta$ was used (26). For all analyses, a distribution phase $(\alpha)$ of $3.5 \pm 0.7 \mathrm{~min}$ was assumed (26). For all three values of $\beta$ used in the deconvolution analysis, 24-h GH production rates were significantly higher in the acromegalic than normal men
$(P<0.05)$. However, there was overlap between acromegalic and normal men with the intermediate and high $\beta$ estimates. In addition, 24-h GH production rates for the acromegalic men did not differ significantly from those of fasting normal men. Acromegalic women had higher $24-\mathrm{h}$ GH production rates compared to normal fed women with the low and intermediate (but not high) $\beta$ estimates; compared to normal fasting women, $\mathrm{GH}$
1. NORMAL MALE FED

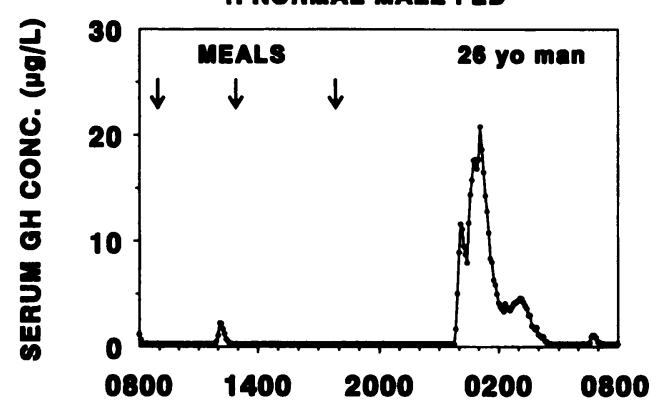

2. NORMAL FEMALE FED

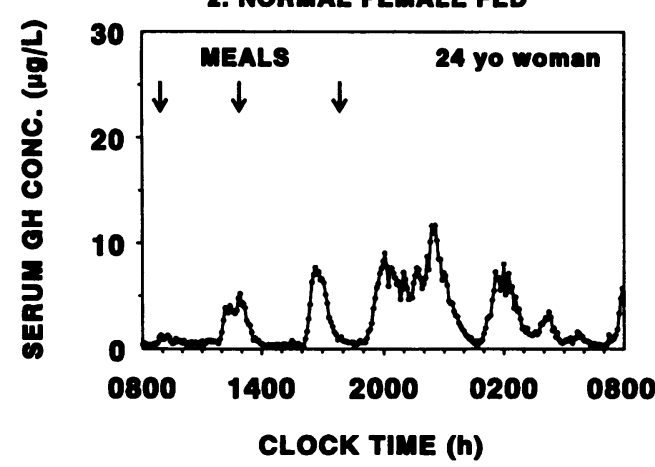

3. NORMAL MALE FASTED (5 DAYS)

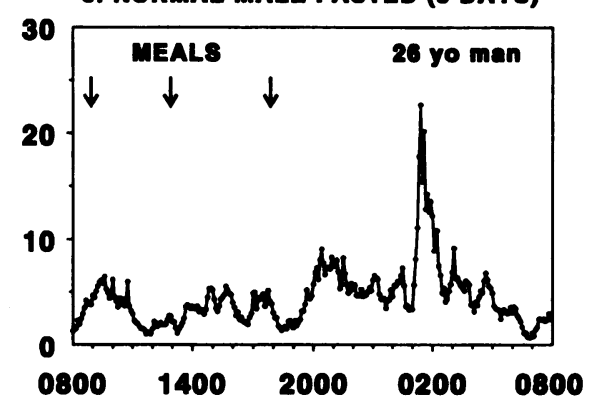

4. NORMAL FEMALE FASTED (5 DAYS)

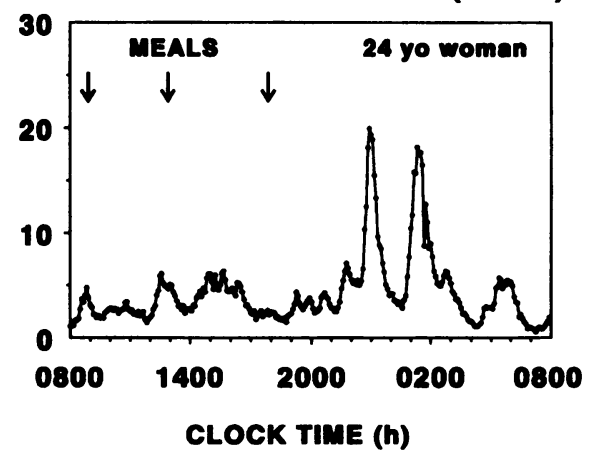

Figure 2. Serum GH concentrations measured by a two-site GH IRMA in blood obtained at 5-min intervals for $24 \mathrm{~h}$ from two normal subjects in the fed state and on the fifth day of a fast to enhance GH secretion physiologically. For panels 1 through 4 , respectively, the following results were obtained (see Figs. 4-7): 24-h GH production rate $\left(t_{1 / 2}=20.7 \mathrm{~min}\right): 94,168$, $274,264 \mu \mathrm{g} \cdot \mathrm{Lv}_{\mathrm{v}}^{-1} \cdot 24 \mathrm{~h}^{-1} ; \mathrm{Z}$-score for basal secretion rates $\left(t_{1 / 2}=20.7 \mathrm{~min}\right)$ : 0.597, 0.521, 1.17, 1.34; ApEn (m = 2): $0.101,0.514,0.736,0.466 ; \mathrm{CV}$ $\left(\left|\Delta X_{i}\right|\right): 2.753,1.070,1.399,1.448$; ratio of highest Fourier amplitude to zero constant: $1.67,0.86,0.47,0.50$. 
8AMPLE OH 8ECRETION RATES

OVER 24 HOURS

$\left(\mu g \cdot L_{v}^{-1} \cdot m / n^{-1}\right)$

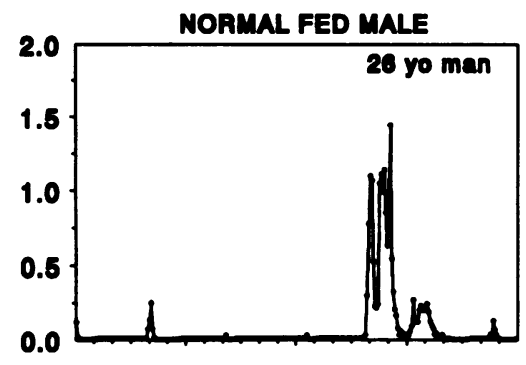

NOAMAL FASTED MALE
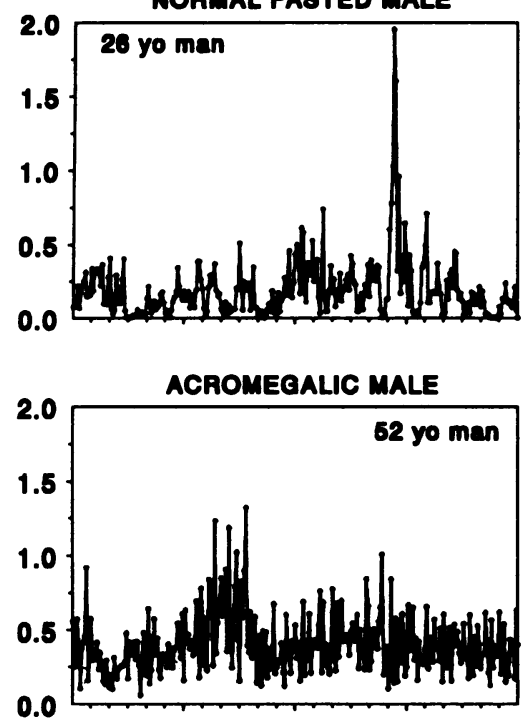

ACROMECALIC MALE IN REMISBION

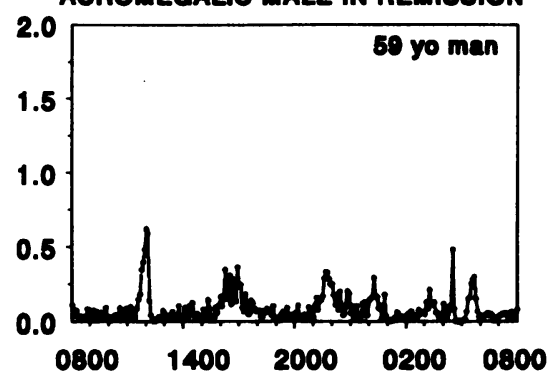

ClOCK TIME (h)

\section{NUMBER OF OCCURRENCES OF SAMPLE GH SECRETION RATE \\ VALUES}
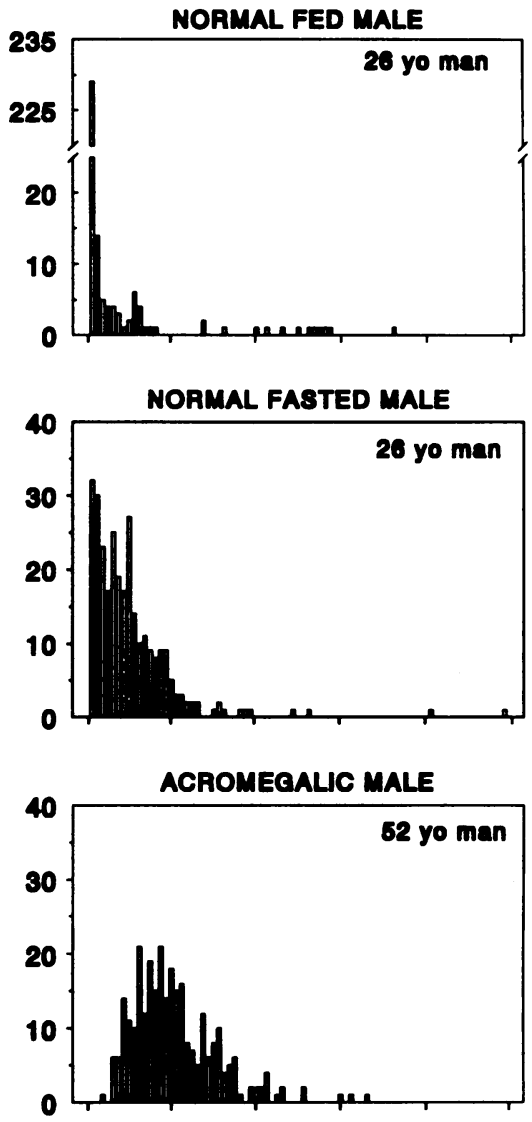

ACROMEgalic male IN Remission

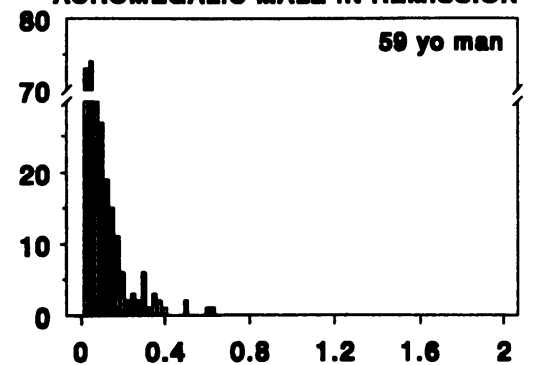

SAMPLE GH SECRETION RATES $\left(\mu g \cdot L_{v}^{-1} \cdot m / n^{-1}\right)$
Figure 3. GH secretion rate profiles, corresponding to the serum GH concentrations shown in Figs. 1 and 2 , for a normal male (fed and fasted), an acromegalic male with active disease, and an acromegalic male in remission. A waveform-independent deconvolution algorithm was used to calculate sample GH secretion rates using a previously determined estimate of the two-component endogenous $\mathrm{GH} t_{1 / 2}$ (distribution phase, $3.5 \pm 0.7 \mathrm{~min}$; elimination phase, $20.7 \pm 0.7 \mathrm{~min}$ ) (26). In the left panels, GH secretion rates, expressed as $\mu \mathrm{g} \mathrm{GH}$ secreted per liter of distribution volume $\left(\mathrm{L}_{\mathrm{v}}\right)$ per $\min \left(\mu \mathrm{g} \cdot \mathrm{L}_{\mathrm{v}}{ }^{-1} \cdot \mathrm{min}^{-1}\right)$, are shown for each 5-min time point of the 24-h sampling period. Note that in the normal male, both in the fed and fasted state, and in the acromegalic male in remission, basal (interpulse) GH secretion rates approach zero on several occasions throughout the 24-h period. In contrast, basal GH secretion rates are consistently elevated throughout the 24-h period in the acromegalic patient with active disease. The right panels give the distributions (histograms) of sample GH secretion rates. Note that the distribution of sample GH secretion rates in active acromegaly is markedly different from that observed in physiologically increased GH secretion (fasting). Acromegalic patients in remission have distributions of secretion rates which resemble those of normal subjects. production rates were greater only with the low $\beta$ estimate $(P<0.05)$. Overlap between acromegalic and normal women occurred at all values of $\beta$. Acromegalic patients in remission had 24-h GH production rates that were either normal or low at all $\beta$ estimates compared with normal fed men and women. However, some overlap between acromegalics in remission and those with active disease was evident. Thus, 24-h GH production rates did not reliably distinguish acromegalic from normal GH secretion.

Estimates of basal GH secretion rates. Fig. 5 depicts estimates of basal (nonpulsatile) GH secretion rates derived from waveform-independent deconvolution analysis with the three estimates of $\beta$. Basal GH secretion was defined to be present when mean lowest interpulse (nadir) secretion rates were significantly greater than zero $(\mathrm{Z}$ score $>1.645, P<0.05)$. All fed normal subjects had basal GH secretion rates that were statistically indistinguishable from zero. With one exception, basal GH secretion was also not significant in fasted normal subjects. In contrast, significant basal secretion was present in $18 / 19$ acromegalic patients with the low $\beta$ estimate, and in 15/ 19 patients with the intermediate and high $\beta$ estimates ( $P$ $<0.05)$. If $P<0.1$ is accepted for statistical significance then 

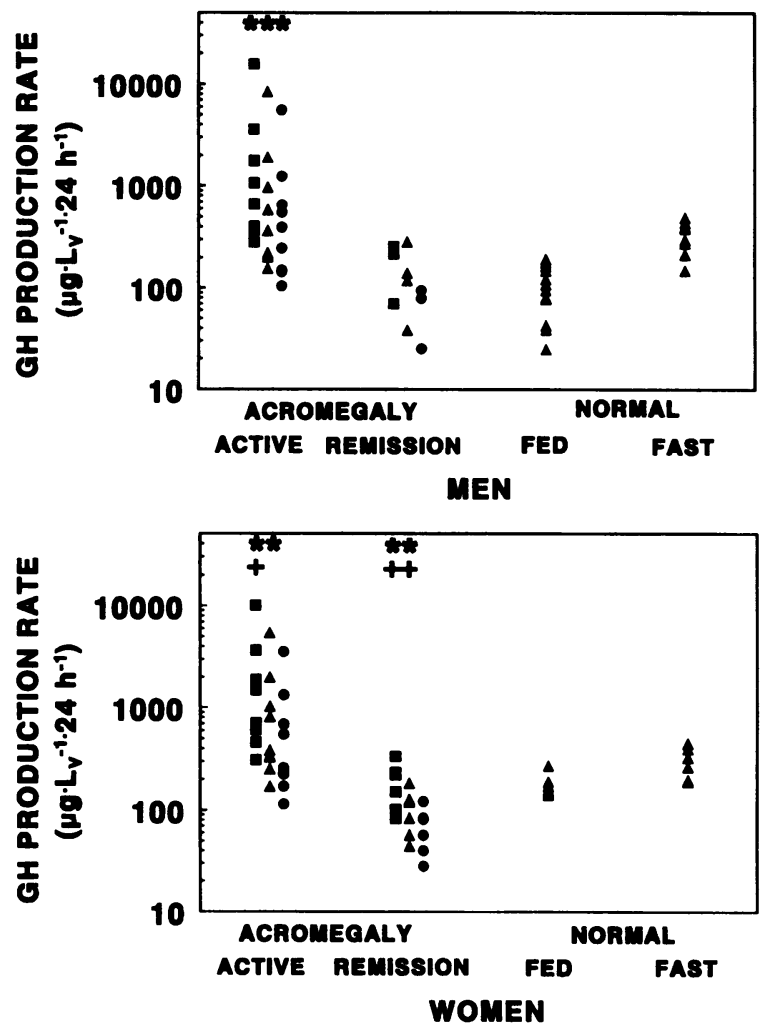

Figure 4. 24-h GH production rates estimated by a waveform-independent deconvolution algorithm using low ( $\square, 8.9 \mathrm{~min})$, intermediate $(\Lambda$, $20.7 \mathrm{~min})$ and high $(\bullet, 33.1 \mathrm{~min})$ estimates of the $\mathrm{GH}$ elimination $t_{1 / 2}$ for four groups of patients: $(a)$ acromegalic patients with active disease; (b) acromegalic patients in biochemical remission; (c) fed normal subjects; and $(d)$ normal subjects on day 5 of a fast to enhance GH secretion physiologically. Calculated $\mathrm{GH}$ production rates are expressed as $\mu \mathrm{g}$ per $\mathrm{L}$ of distribution volume $\left(\mathrm{L}_{\mathrm{v}}\right)$ per $24 \mathrm{~h}\left(\mu \mathrm{g} \cdot \mathrm{Lv}_{\mathrm{v}}^{-1} \cdot 24 \mathrm{~h}^{-1}\right)$; note the logarithmic scale. Although 24-h GH production rates tended to be higher in acromegalic patients there was significant overlap between values for acromegalic and normal subjects in both the fed and fasted states. ${ }^{*} P<0.05$ versus normal fed subjects; $\uparrow P<0.05$ versus normal fasted subjects.

significant basal secretion was present in $18 / 19,19 / 19$, and $18 /$ 19 acromegalics for the low, intermediate and high $\beta$ estimates, respectively. All acromegalics in remission had nonsignificant rates of basal $\mathrm{GH}$ secretion at the $P=0.05$ level.

Approximate entropy (ApEn) results. ApEn values ( $m=2$ and $r=20 \%$ of the average SD of the GH time-series) calculated for the four groups of patients are shown in Fig. 6. A table summarizing specific subgroup (e.g., by gender) comparisons for all of the ApEn results $(m=1$ and $m=2)$ is included in Appendix B. Here we discuss ApEn results with $m=2$; the ApEn results with $m=1$ are qualitatively similar (Appendix B). Acromegalic patients with active disease had ApEn values $(0.97 \pm 0.18)$ which were significantly greater than those for normal subjects in either the fed state $\left(0.33 \pm 0.18, P<10^{-12}\right)$ or the fasted state $\left(0.48 \pm 0.2, P<10^{-7}\right)$. This suggests that GH concentration profiles in acromegaly are more irregular or disorderly than in normal subjects. In contrast, pulsatile GH secretion in normal subjects, even when enhanced by fasting, is more regular. All normal subjects (fed and fasted) had ApEn
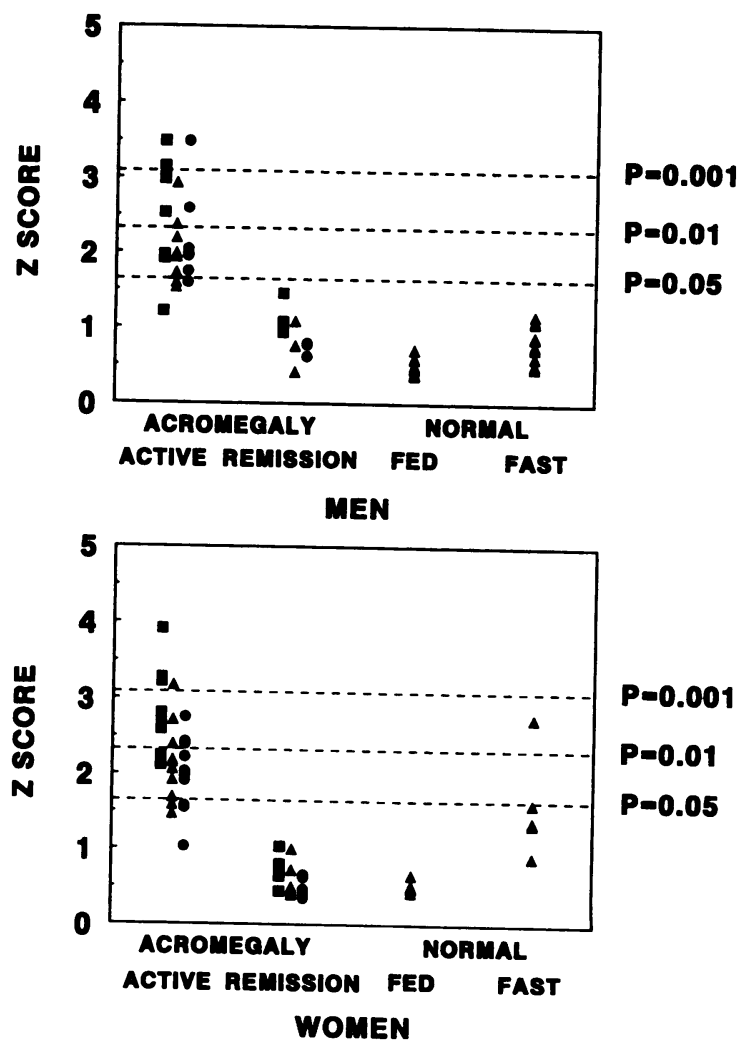

Figure 5. Standard deviate (Z) scores of basal (nonpulsatile) GH secretion rates estimated by a waveform-independent deconvolution algorithm using low (৫, $8.9 \mathrm{~min})$, intermediate $(\Delta, 20.7 \mathrm{~min})$ and high $(\bullet$, $33.1 \mathrm{~min}$ ) estimates of the GH elimination $t_{1 / 2}$ for the 4 groups of patients described in Fig. 4. Basal GH secretion is defined to be present when mean lowest (nadir) interpulse secretion rates were significantly greater than zero ( $\mathrm{Z}$ score $>1.645, P<0.05$ ). Note that basal GH secretion rates were significantly nonzero in acromegalic but not in normal subjects, even when GH secretion was enhanced by fasting (with one exception).

values below 0.77; all but one acromegalic patient had ApEn values above 0.77 . The ApEn analysis separated acromegalic from normal GH secretion with a sensitivity of $95 \%$ and a specificity of $100 \%$. The one acromegalic patient with a lower ApEn value was unusual in that he had McCune-Albright syndrome and was unable to undergo transsphenoidal surgery due to severe sphenoid bone hyperostosis. Acromegalic patients in biochemical remission had ApEn values $(0.68 \pm 0.16)$ that were intermediate between those of acromegalics with active disease and normal fed subjects $(P<0.001)$. Nonetheless, ApEn values for patients in remission overlapped with those of acromegalics with active disease and with normal subjects. In normal fed subjects, a significant gender difference was observed as females had greater ApEn values $(0.47 \pm 0.17)$ than males $(0.24 \pm 0.12, P<0.01)$. Of note, more samples had undetectable quantities of $\mathrm{GH}$ in the fed males $(46 \pm 7.6 \%)$ than in the fed females $(17 \pm 6.8 \%)$. No gender differences were evident for either fasted normal subjects or active acromegalic patients. Fasting increased ApEn values significantly compared to the fed state in normal male subjects but not in the normal women (Appendix B). 

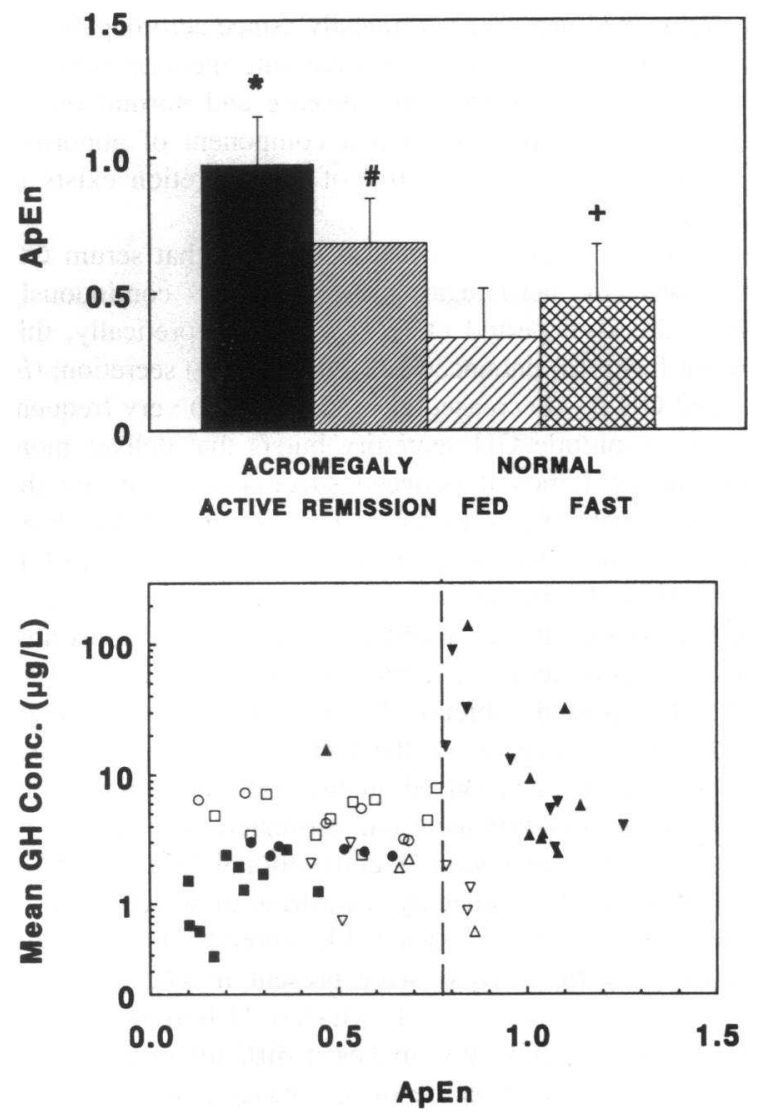

Figure 6. Approximate entropy (ApEn [ $m=2, r=20 \%$ SD]) values for the four groups of patients described in Fig. 4. The top panel depicts mean ApEn values ( $\pm S D$ ) for the four groups. ApEn values were significantly higher in acromegalics with active disease compared to normal (fed or fasted) subjects, indicating that GH secretion in acromegaly is more disorderly than normal pulsatile GH secretion, even when the latter is enhanced by fasting. Acromegalic patients in remission had intermediate values. ${ }^{*} P<10^{-7}$ vs. normal fed and fasted subjects; $† P$ $<0.02$ vs. normal fed subjects; $\# P<0.001$ vs. active acromegalics and normal fed subjects. The bottom panel shows individual subject ApEn values versus mean GH concentrations on a logarithmic scale; the broken line separates all but one acromegalic with active disease from normal (both fed and fasted) subjects. ( $\Delta$ ) Acromegalic males; $(\nabla)$ acromegalic females; ( $\square$ ) normal fed males; ( $\square$ ) normal fasted males; $(\bullet)$ normal fed females; $(O)$ normal fasted females; $(\Delta)$, acromegalic males in remission; $(\nabla)$ acromegalic females in remission.

Coefficient of variation of incremental change $\left[C V\left(\left|\Delta X_{\mathrm{i}}\right|\right)\right]$ results. CV $\left(\left|\Delta \mathrm{X}_{\mathrm{i}}\right|\right)$ values calculated for the four groups of patients are shown in Fig. 7; specific subgroup (e.g. by gender) comparisons are included in the Appendix B. Acromegalic patients with active disease had $\mathrm{CV}\left(\left|\Delta \mathrm{X}_{\mathrm{i}}\right|\right)$ values $(0.95 \pm 0.15)$ which were significantly lower than those of normal subjects in either the fed $(1.73 \pm 0.61)$ or fasted $(1.84 \pm 0.86)$ states $(P$ $<0.001)$. This indicates that acromegalics have relatively constant changes in GH concentrations across successive measurements. In contrast, the large bursts of $\mathrm{GH}$ secretion in normal subjects produce higher values of $C V\left(\left|\Delta \mathbf{X}_{\mathrm{i}}\right|\right)$. All normal subjects (fed or fasted) had CV $\left(\left|\Delta X_{i}\right|\right)$ values above 1.05. All but four acromegalic patients had $\mathrm{CV}\left(\left|\Delta \mathrm{X}_{\mathrm{i}}\right|\right)$ values below 1.05; one of these four was the patient with McCune-Albright
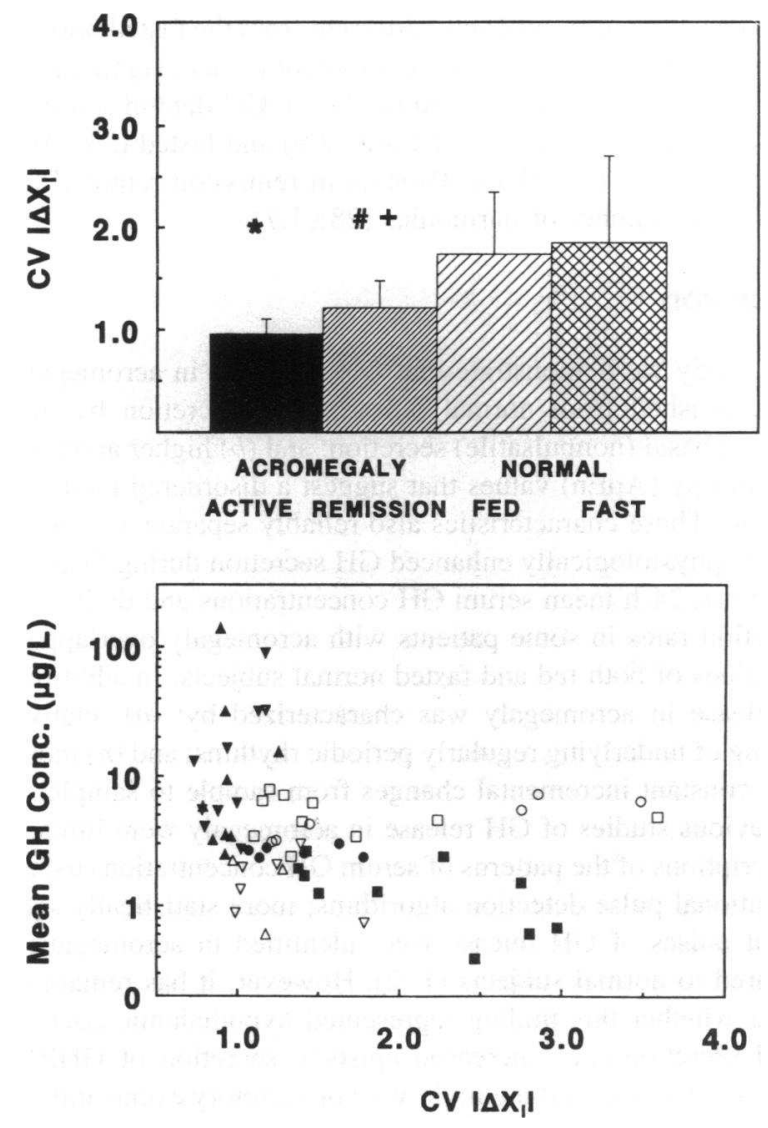

Figure 7. Coefficients of variation of serial incremental changes (CV $\left.\left(\left|\Delta \mathbf{X}_{\mathrm{i}}\right|\right)\right)$ in serum $\mathrm{GH}$ concentrations calculated for the four groups of patients described in Fig. 4. The top panel depicts mean CV $\left(\left|\Delta \mathrm{X}_{\mathrm{i}}\right|\right)$ values $( \pm S D)$ for the four groups. $C V\left(\left|\Delta X_{i}\right|\right)$ values were significantly lower in acromegalics with active disease compared to normal (fed or fasted) subjects, indicating that acromegalic patients have relatively constant incremental changes in GH concentrations across successive measurements. In contrast, the large bursts of GH secretion in normal subjects produce higher values of $\mathrm{CV}\left(\left|\Delta \mathrm{X}_{\mathrm{i}}\right|\right)$. Acromegalic patients in remission had intermediate values. ${ }^{*} P<0.001$ vs. normal fed and fasted subjects; $\nmid P<0.005$ vs. normal fed subjects; $\# P<0.05$ vs. active acromegalics. The bottom panel shows individual subject $C V\left(\left|\Delta X_{i}\right|\right)$ values versus mean $\mathrm{GH}$ concentrations on a logarithmic scale. The symbols are defined in the legend for Fig. 6.

syndrome. Thus, $\mathrm{CV}\left(\left|\Delta \mathrm{X}_{\mathrm{i}}\right|\right)$ did not separate acromegalic from normal subjects so nearly completely as ApEn. Acromegalic patients in biochemical remission had $\mathrm{CV}\left(\left|\Delta \mathrm{X}_{\mathrm{i}}\right|\right)$ values $(1.21 \pm 0.26)$ that were intermediate between those of acromegalics with active disease and normal fed subjects $(P<0.05)$.

Fourier series analysis results. Fourier analysis of underlying periodic rhythms revealed that ratios of the highest Fourier amplitude $(\mu \mathrm{g} / \mathrm{l})$ to the zero order constant (weighted mean GH concentration) were significantly lower in acromegalic $(0.22 \pm 0.02)$ compared to fed $(1.08 \pm 0.08)$ and fasted $(0.76 \pm 0.13)$ normal subjects $(P<0.05)$. This suggests that underlying periodic rhythms in GH secretion were damped in comparison to the markedly enhanced basal secretion. For the acromegalics in remission, this ratio $(0.50 \pm 0.05)$ was intermediate between but significantly different from the values for the acromegalics with active disease and the fed normal subjects 
$(P<0.05)$, but not significantly different from the fasted normal subjects. Another interesting observation of unclear significance is that fewer harmonics were required to fit GH data in acromegalics (16 \pm 1.8$)$ compared to fed $(42 \pm 2.9)$ and fasted (33 \pm 0.9$)$ normal subjects $(P<0.05)$. Patients in remission required an intermediate number of harmonics $(28 \pm 1.7)$.

\section{Discussion}

In this study we demonstrate that GH secretion in acromegaly is distinguished from normal pulsatile GH secretion by: $(a)$ enhanced basal (nonpulsatile) secretion; and (b) higher approximate entropy (ApEn) values that suggest a disordered mode of secretion. These characteristics also reliably separate acromegaly from physiologically enhanced $\mathrm{GH}$ secretion during fasting. In contrast, 24-h mean serum GH concentrations and daily GH production rates in some patients with acromegaly overlapped with values of both fed and fasted normal subjects. In addition, GH release in acromegaly was characterized by: $(a)$ relative damping of underlying regularly periodic rhythms; and $(b)$ more nearly constant incremental changes from sample to sample.

Previous studies of $\mathrm{GH}$ release in acromegaly were limited to descriptions of the patterns of serum GH concentrations using conventional pulse detection algorithms; more statistically significant pulses of $\mathrm{GH}$ release were identified in acromegalics compared to normal subjects $(1,2)$. However, it has remained unclear whether this finding represented hypothalamic control of GH secretion (i.e., increased episodic secretion of GHRH and/or more somatostatin withdrawal) or secretory events intrinsic to the adenomatous tissue. Furthermore, since serum GH concentrations become undetectable in most conventional immunoassays for portions of the day in normal subjects (21), the relatively higher GH pulse frequency in acromegalic versus normal subjects may be related to underestimation of the $\mathrm{GH}$ pulse frequency in the latter $(1,13)$. In addition, previous studies did not address, in an analytical manner, the possibility that "pulses" detected by pulse detection algorithms may arise from distinctly different secretory mechanisms in different types of patients. The higher ApEn scores in our acromegalic patients indicate that in this disease $\mathrm{GH}$ is secreted in a distinctly more irregular manner than in normal subjects. Physiological enhancement of GH secretion, as occurs with fasting, likely results from decreased somatostatin and/or increased GHRH secretion $(22,34)$, as well as reduced negative feedback by IGF-I (35). Since our fasted subjects had ApEn scores that were significantly lower than those of acromegalic patients, this new finding suggests that GH secretion in acromegaly does not arise from these normal hypothalamic control mechanisms. A plausible interpretation of these observations would be that "pulses" observed in serum GH concentration profiles of acromegalic patients arise primarily from irregular bursts of secretory activity by adenomatous tissue. In support of this hypothesis, normal perifused monkey anterior hemipituitaries secrete GH in a spontaneously pulsatile manner (16). This does not exclude some measure of hypothalamic control, since GHRH can increase, and somatostatin can decrease, serum GH concentrations in acromegalics $(11-13,36)$. However, elevated blood concentrations of GH and IGF-I would be expected to result in decreased GHRH and enhanced somatostatin secretion via normal feedback to the hypothalamus. Thus, it is likely that the usual ordered control of GH secretion by GHRH and somatostatin is greatly diminished in active acromegaly. Since acromegalics in remission had ApEn scores that were intermediate between those of acromegalics with active disease and normal fed or fasted subjects, it is possible that a component of abnormal or disorderly hypothalamic control of GH secretion exists in acromegaly.

Previous investigations have also reported that serum GH concentrations in acromegaly are elevated continuously throughout the 24-h period $(1,2,11-13)$. Theoretically, this could result from: (a) enhanced basal (interpulse) secretion; (b) a prolonged GH $t_{1 / 2}$ (decreased clearance); or (c) very frequent and/or high amplitude GH secretory bursts that deliver more GH than can be removed between successive events by the usual rate of metabolic clearance. The last model has been proposed to account for the continuously elevated serum GH concentrations in fasting normal subjects (22). Here, we report that statistically significant basal GH secretion is demonstrable in virtually all acromegalic patients and is absent in almost all fed and fasted normal subjects. The use of low, intermediate or high literature estimates of the GH elimination $t_{1 / 2}$ in our deconvolution analysis produced qualitatively the same results. Thus, significant basal GH secretion, estimated from serum GH concentrations measured with a conventional GH IRMA, is highly suggestive of acromegaly regardless of which $t_{1 / 2}$ estimate is used. In this study, undetectable amounts of GH (below the sensitivity of the IRMA) were present in $46 \pm 7.6 \%$ and $17 \pm 6.8 \%$ of blood samples withdrawn over $24-\mathrm{h}$ in the fed men and women, respectively; this makes it difficult to accurately estimate the amount and nature of low basal GH secretion in normal subjects. In the fasted state, GH was measurable in 98$99 \%$ of samples in both men and women. Recently, GH assays with enhanced sensitivity have become available that enable serum GH concentrations to be measured in all samples obtained throughout a 24-h period. Preliminary evidence, obtained with a GH chemiluminescence assay with a sensitivity of 0.005 $\mu \mathrm{g} / \mathrm{l}$ and deconvolution analysis, indicates that very low levels of basal GH secretion exist in normal subjects (37). Thus, it is likely that basal GH secretion is present in normal subjects but contributes very little ( $<5 \%$ in young adults) to the overall 24 $\mathrm{h}$ GH production rate (37). In contrast, basal GH secretion is markedly enhanced in acromegaly and accounts for a large portion of the 24-h GH production rate. As estimated in our study, basal secretion accounted for 69,45 , and $38 \%$ of $24-h$ mean $\mathrm{GH}$ secretion rates in the acromegalics for the low, normal and high $t_{1 / 2}$ estimates, respectively. Assuming that basal GH secretion is not regulated by intermittent GHRH release, these results provide further support for our model of a primarily autonomous mode of GH secretion by somatotroph adenomas.

We previously reported, using Fourier time series analysis, that the amplitude of the 24-h rhythm of $\mathrm{GH}$ release in patients with active acromegaly was decreased relative to mean $\mathbf{G H}$ concentrations (1). In the present study, Fourier analysis revealed that the ratio of the highest Fourier amplitude to the zero order constant (equivalent to a weighted mean GH concentration) was significantly lower in patients with acromegaly than in normal fed or fasted subjects, suggesting that enhanced basal GH secretion damped underlying periodic rhythms of GH release. Since neural input is believed to be responsible, at least in part, for circadian and ultradian rhythmicity (38), these findings suggest that some loss of hypothalamic regulation has occurred. This interpretation is supported by the lower values of $\mathrm{CV}$ 
$\left(\left|\Delta X_{i}\right|\right)$ in the acromegalic patients which indicates that the pulsatile component of $\mathrm{GH}$ release in acromegaly results in more uniformity of serial incremental changes in GH concentrations compared to normal pulsatile GH secretion. This finding is compatible with our model of largely autonomous GH secretion by somatotroph adenomas.

Recent advances in the molecular biology of pituitary adenomas provide further support for acromegaly as a primary pituitary disease. All somatotroph adenomas studied to date have been monoclonal in origin $(39,40)$. In $30-40 \%$ of somatotroph adenomas, somatic mutations in the stimulatory $G$ protein $\left(\mathrm{G}_{\mathrm{s}}\right)$ gene may convert this gene into a putative oncogene, termed $g s p(40-45)$. The mutant $\mathrm{G}_{\mathrm{s}}$ is unable to hydrolyze GTP, which results in constitutive activation of adenylate cyclase, high intracellular cAMP concentrations, and high in vitro GH secretion rates that are not significantly augmented by GHRH, since cAMP is the pathway that mediates GHRH action (41, $42,46)$. Decreased methylation of the $\mathrm{GH}$ gene may result in increased GH gene expression in somatotroph adenomas (40, 47). However, a role for GHRH as a tumor promoter cannot be excluded, particularly since pituitary adenomas occur in mice transgenic for GHRH (48) and in patients with excessive central GHRH hypersecretion on a congenital basis (49) or in association with hypothalamic gangliocytomas (50).

In vitro studies of human somatotroph adenoma cells support our model of disordered, semi-autonomous GH secretion. Under identical cell culture conditions, adenoma cells secrete less $\mathrm{GH}$ in response to GHRH than normal rat pituitary cells (51). Although GHRH increases the amount of GH secreted per cell in both normal and adenomatous pituitary cells, the percentage of cells secreting $\mathrm{GH}$ is increased only in normal somatotrophs $(52,53)$. In normal rat somatotrophs the frequency and amplitude of intracellular calcium ion oscillations correlates with the amount of GH secreted spontaneously per cell (53). In contrast, high levels of basal GH secretion occur in human somatotroph adenomas with only $0-5 \%$ of cells exhibiting spontaneous calcium oscillations (54). This loss of normal stimulus-secretion coupling in adenoma cells may produce a less ordered pattern of secretion, which we are detecting in our analysis of serial serum GH concentrations by higher ApEn scores.

Although a variety of clinical studies of GH release in acromegaly have been individually interpreted to suggest that $\mathrm{GH}$ pulses in acromegaly arise from hypothalamic regulation, we suggest that alternatively these studies can support our hypothesis that these pulses likely are of. pituitary origin. For example, in acromegaly, GH pulse frequency is unaffected by continuous infusions of GHRH (11) or the somatostatin analogue, octreotide $(12,13)$. Furthermore, changes in plasma IGF-I concentrations, whether increases during pregnancy or decreases during fasting, do not alter the GH pulse frequency $(14,15)$. Thus, although the amplitude of GH pulses may be regulated in part by these factors, the origin of the pulses is likely intrinsic to the pituitary adenoma and less susceptible to extrinsic regulation. Administration of a GHRH antagonist to acromegalic patients may provide another means to test this hypothesis, although in normal subjects such treatment decreased GH pulse amplitudes but did not change pulse frequency (55). Variable $\mathrm{GH}$ responses to GHRH have been reported in acromegalic patients (36). This may reflect in part the fact that $g s p$ positive tumors are less responsive to GHRH (44). However, the presence or absence of the gsp mutation does not appear to alter the pattern of GH release consistently in any other significant way. Both lower $(40,43)$ and higher $(44)$ basal serum GH concentrations have been reported in patients with gsp positive (versus gsp negative) tumors. A recent preliminary report found no differences in attributes of pulsatile GH release, as determined by Cluster analysis of serum GH levels measured at 10-20 min intervals over $24 \mathrm{~h}$, in six patients with gsp positive tumors compared to 10 patients with gsp negative tumors (56). In our study, ApEn scores for patients with active acromegaly were grouped in a fairly narrow range of 0.75 to 1.25 with the exception of a single patient with McCune-Albright syndrome whose ApEn score was 0.5 . Thus, it appears likely that most patients with somatotroph adenomas, irrespective of the mutation responsible for tumorigenesis, have similar temporal patterns of $\mathrm{GH}$ release. The McCune-Albright syndrome is a sporadic disease characterized by polyostotic fibrous dysplasia, café au lait pigmentation of the skin, and multiple endocrinopathies. Recently, mutations of the $\mathrm{G}_{\mathrm{s}} \alpha$ subunit gene have been identified in pituitary, thyroid, ovarian and adrenal tissues from patients with this syndrome (57). We hypothesize that our patient had somatotroph hyperplasia since his ApEn score was not in the range of the other adenomas; mammosomatotroph hyperplasia has previously been reported in a patient with McCune-Albright syndrome (58). Unfortunately, no tissue could be obtained from the patient in the present report because his severe polyostotic fibrous dysplasia made transsphenoidal surgery impossible.

The possible clinical utility of these analytical methods in the diagnosis of either early acromegaly or recurrent acromegaly after initially successful transsphenoidal surgery will require further study. Significant basal GH secretion was not detected in any of our acromegalic patients in clinical and biochemical remission. Although our controls included fasting subjects with uniformly detectable serum GH concentrations, these analyses will need to be repeated with more sensitive $\mathrm{GH}$ assays to allow a proper comparison with low levels of basal GH release in normal fed subjects. It is unlikely that the use of more sensitive assays will change our conclusions with ApEn since highly significant differences were found between fasting normal subjects and acromegalic patients. Our patients in remission had ApEn scores that were intermediate between those of patients with active acromegaly and normal fed subjects but significantly different from both groups. Does this indicate residual pituitary tumor tissue, which is sufficient to alter the pattern of $\mathbf{G H}$ release but not increase IGF-I levels? Or does this reflect an element of altered hypothalamic regulation, which is unmasked by the removal of pituitary tumor tissue? It is possible that deconvolution analysis of basal GH secretion and analysis of the regularity of GH release by ApEn will be useful in situations where early acromegaly is otherwise difficult to distinguish from normal GH release. The scale-independence of ApEn may make this statistic particularly useful in mild acromegaly (early disease and residual or recurrent disease after transsphenoidal surgery) when mean serum GH concentrations are not clearly elevated beyond the range observed in normal subjects.

We conclude that GH secretion in acromegaly is highly irregular and disorderly with accompanying significant basal secretion. We hypothesize that somatotroph adenomas secrete $\mathrm{GH}$ at high constitutive rates in a random, episodic manner with decreased control by the normal orderly release of GHRH and somatostatin by the hypothalamus. Our results suggest that GH 
"pulses" detected by pulse detection algorithms in normal and tumoral states may arise from fundamentally different control mechanisms.

\section{Appendix A}

Approximate entropy (ApEn) definition. Given $N$ data points $u(1)$, $\mathrm{u}(2), \ldots, ., u(N)$, two input parameters, $m$ and $r$, must be fixed to compute ApEn [denoted precisely by $\operatorname{ApEn}(m, r, N)$ ]. To define ApEn, first form vector sequences $\mathrm{x}(1)$ through $\mathrm{x}(N-m+1)$ from the $u(i)$, defined by $\mathrm{x}(i)=[u(i), \ldots, u(i+m-1)]$. These vectors represent $m$ consecutive $u$ values, commencing with the ith point. Define the distance $d[\mathbf{x}(i)$, $\mathrm{x}(j)$ ] between vectors $\mathrm{x}(i)$ and $\mathrm{x}(j)$ as the maximum difference in their respective scalar components. Use the sequence $\mathrm{x}(1), \mathrm{x}(2), \ldots, \mathrm{x}(N$ $-m+1)$ to construct, for each $i \leq \mathrm{N}-m+1, C_{i}^{m}(r)=$ \{number of $\mathrm{x}(j)$ such that $d[\mathrm{x}(i), \mathrm{x}(j)] \leq r\} /(N-m+1)$. The $C_{i}^{m}(r)$ values measure within a tolerance $r$ the regularity, or frequency, of patterns similar to a given pattern of window length $m$. Next, define $\Phi^{m}(r)$ as the average value of $\ln C_{i}^{m}(r)$, where $\ln$ is the natural logarithm. We define approximate entropy by $\operatorname{ApEn}(m, r, N)=\Phi^{m}(r)-\Phi^{m+1}(r)$.

When $m=2$, as we employ, we interpret ApEn as a measure of the difference between the probability that runs of value of length 2 will recur within tolerance $r$ and the probability that runs of length 3 will recur (to the same tolerance). A high degree of regularity in the data would imply that a given run of length 2 would often continue with nearly the same third value, producing a low value of ApEn.

\section{Appendix B}

Table I. Subgroup Comparisons for Approximate Entropy (ApEn) Results, Coefficients of Variation of Incremental Change [CV ( $\left.\left.\left|\Delta X_{i}\right|\right)\right]$, and Mean GH Concentrations

\begin{tabular}{|c|c|c|c|c|c|}
\hline Comparison & $n$ & ApEn, $m=1$ & ApEn, $m=2$ & $\mathrm{CV}\left(\left|\Delta \mathrm{X}_{\mathrm{i}}\right|\right)$ & Mean GH \\
\hline & & & & & $\mu g / l$ \\
\hline Fed normals vs. & 20 & $0.454 \pm 0.205$ & $0.334 \pm 0.179$ & $1.733 \pm 0.611$ & $2.15 \pm 0.99$ \\
\hline Active acromegaly & 19 & $1.370 \pm 0.322$ & $0.972 \pm 0.175$ & $0.954 \pm 0.145$ & $22.23 \pm 34.99$ \\
\hline Overall & & $P=0.126 \times 10^{-10}$ & $P=0.180 \times 10^{-12}$ & $P=0.164 \times 10^{-4}$ & $P=0.0222$ \\
\hline Fed normals vs. & 12 & $0.347 \pm 0.132$ & $0.242 \pm 0.118$ & $1.997 \pm 0.638$ & $1.70 \pm 0.92$ \\
\hline Active acromegaly & 9 & $1.354 \pm 0.406$ & $0.969 \pm 0.206$ & $0.946 \pm 0.130$ & $23.84 \pm 44.22$ \\
\hline Males & & $P=0.456 \times 10^{-4}$ & $P=0.655 \times 10^{-6}$ & $P=0.117 \times 10^{-3}$ & $P=0.1715$ \\
\hline Fed normals vs. & 8 & $0.615 \pm 0.193$ & $0.472 \pm 0.170$ & $1.337 \pm 0.274$ & $2.82 \pm 0.69$ \\
\hline Active acromegaly & 10 & $1.383 \pm 0.245$ & $0.975 \pm 0.154$ & $0.961 \pm 0.164$ & $20.77 \pm 26.55$ \\
\hline Females & & $P=0.145 \times 10^{-5}$ & $P=0.125 \times 10^{-4}$ & $P=0.586 \times 10^{-2}$ & $P=0.0612$ \\
\hline Remission vs. & 9 & $0.873 \pm 0.184$ & $0.683 \pm 0.164$ & $1.209 \pm 0.261$ & $1.63 \pm 0.80$ \\
\hline Active acromegaly & 19 & $1.370 \pm 0.322$ & $0.972 \pm 0.175$ & $0.954 \pm 0.145$ & $22.23 \pm 34.99$ \\
\hline Overall & & $P=0.245 \times 10^{-4}$ & $P=0.538 \times 10^{-3}$ & $P=0.0201$ & $P=0.0195$ \\
\hline Remission vs. & 9 & $0.873 \pm 0.184$ & $0.683 \pm 0.164$ & $1.209 \pm 0.261$ & $1.63 \pm 0.80$ \\
\hline Fed normals & 20 & $0.454 \pm 0.205$ & $0.334 \pm 0.179$ & $1.733 \pm 0.611$ & $2.15 \pm 0.99$ \\
\hline Overall & & $P=0.403 \times 10^{-4}$ & $P=0.805 \times 10^{-4}$ & $P=0.323 \times 10^{-2}$ & $P=0.1524$ \\
\hline Fasted normals vs. & 16 & $0.586 \pm 0.246$ & $0.476 \pm 0.200$ & $1.845 \pm 0.858$ & $5.04 \pm 1.71$ \\
\hline Active acromegaly & 19 & $1.370 \pm 0.322$ & $0.972 \pm 0.175$ & $0.954 \pm 0.145$ & $22.23 \pm 34.99$ \\
\hline Overall & & $P=0.227 \times 10^{-8}$ & $P=0.123 \times 10^{-7}$ & $P=0.864 \times 10^{-3}$ & $P=0.0464$ \\
\hline Fasted normals vs. & 10 & $0.592 \pm 0.227$ & $0.485 \pm 0.194$ & $1.651 \pm 0.759$ & $5.09 \pm 1.79$ \\
\hline Active acromegaly & 9 & $1.355 \pm 0.406$ & $0.969 \pm 0.206$ & $0.946 \pm 0.130$ & $23.84 \pm 44.22$ \\
\hline Males & & $P=0.301 \times 10^{-3}$ & $P=0.710 \times 10^{-4}$ & $P=0.0169$ & $P=0.2391$ \\
\hline Fasted normals vs. & 6 & $0.578 \pm 0.298$ & $0.461 \pm 0.227$ & $2.167 \pm 0.984$ & $4.97 \pm 1.74$ \\
\hline Active acromegaly & 10 & $1.383 \pm 0.246$ & $0.975 \pm 0.154$ & $0.962 \pm 0.164$ & $20.77 \pm 26.55$ \\
\hline Females & & $P=0.329 \times 10^{-3}$ & $P=0.127 \times 10^{-2}$ & $P=0.0297$ & $P=0.0930$ \\
\hline Fed normals vs. & 16 & $0.428 \pm 0.197$ & $0.308 \pm 0.164$ & $1.817 \pm 0.635$ & $1.88 \pm 0.85$ \\
\hline Fasted normals & 16 & $0.586 \pm 0.246$ & $0.476 \pm 0.199$ & $1.844 \pm 0.858$ & $5.04 \pm 1.71$ \\
\hline Overall & & $P=0.0535$ & $P=0.0148$ & $P=0.920$ & $P=0.121 \times 10^{-5}$ \\
\hline Fed normals vs. & 10 & $0.331 \pm 0.133$ & $0.229 \pm 0.114$ & $2.087 \pm 0.641$ & $1.44 \pm 0.75$ \\
\hline Fasted normals & 10 & $0.592 \pm 0.227$ & $0.485 \pm 0.193$ & $1.651 \pm 0.759$ & $5.09 \pm 1.79$ \\
\hline Males & & $P=0.00722$ & $P=0.00270$ & $P=0.183$ & $P=0.658 \times 10^{-4}$ \\
\hline Fed normals vs. & 6 & $0.588 \pm 0.188$ & $0.442 \pm 0.153$ & $1.369 \pm 0.289$ & $2.63 \pm 0.26$ \\
\hline Fasted normals & 6 & $0.578 \pm 0.297$ & $0.461 \pm 0.227$ & $2.167 \pm 0.984$ & $4.97 \pm 1.74$ \\
\hline Females & & $P=0.944$ & $P=0.869$ & $P=0.106$ & $P=0.209$ \\
\hline
\end{tabular}

Results are mean $\pm \mathrm{SD}$; P values based on two-sided $t$ test, unknown, unequal variances. 


\section{Acknowledgments}

We thank Ms. Sandra W. Jackson and the staff of the General Clinical Research Center of the University of Virginia for their expert assistance. We also thank Ms. Ginger Bauler, Ms. Catherine Kern, Mr. Anthony Amos, and Ms. Marjorie Gingell for performing the GH assays, Ms. Suzan Pezzoli for technical assistance, and Mr. David G. Boyd for assistance with CLINFO.

This work was supported by National Institutes of Health grants RR-00847 (to the University of Virginia General Clinical Research Center), AG-10997 (to M. L. Hartman), DK-32632 (to M. O. Thorner), Research Career Development Award 1-K04-HD00634 (to J. D. Veldhuis), DK-38942 (to the University of Virginia Diabetes Endocrinology Research Center), and the National Science Foundation Center for Biological Timing (grant DIR89-20162).

\section{References}

1. Hartman, M. L., J. D. Veldhuis, M. L. Vance, A. C. S. Faria, R. W. Furlanetto, and M. O. Thorner. 1990. Somatotropin pulse frequency and basal concentrations are increased in acromegaly and are reduced by successful therapy. J. Clin. Endocrinol. Metab. 70:1375-1384.

2. Barkan, A. L., S. E. Stred, K. Reno, M. Markovs, N. J. Hopwood, R. P. Kelch, and I. Z. Beitins. 1989. Increased growth hormone pulse frequency in acromegaly. J. Clin. Endocrinol. Metab. 69:1225-1233.

3. Glick, S. M., J. Roth, and E. T. Lonergan. 1964. Survival of endogenous human growth hormone in plasma. J. Clin. Endocrinol. Metab. 24:501-505.

4. MacGillivray, M. H., L. A. Frohman, and J. Doe. 1970. Metabolic clearance and production rates of human growth hormone in subjects with normal and abnormal growth. J. Clin. Endocrinol. Metab. 30:632-638.

5. Yen, S. S. C., T. M. Siler, and G. W. DeVane. 1974. Effect of somatostatin in patients with acromegaly. $N$. Engl. J. Med. 290:935-938.

6. Roelfsema, F., D. Van Der Heide, P. J. Lowry, H. Van Dulken, and J. Schröder-Van Der Elst. 1988. Plasma growth hormone half-life after selective removal of adenoma in acromegalics determines the outcome of surgery. Clin. Endocrinol. (Oxf.). 28:51-59.

7. Lüdecke, D., D. Kautzky, W. Saeger, and D. Schrader. 1976. Selective removal of hypersecreting pituitary adenomas? Acta. Neurochir. 35:27-42.

8. Lanzi, R., A. C. Andreotti, M. Losa, A. Moreschi, and A. E. Pontiroli. 1992. Metabolic clearance rate (MCR) of growth hormone (GH) during constant methionyl-GH infusions in normal subjects and in acromegalic patients. Prog. 74th Meet. Endocr. Soc. 228. (Abstr. 706).

9. Refetoff, S., and P. H. Sönksen. 1970. Disappearance rate of endogenous and exogenous human growth hormone in man. J. Clin. Endocrinol. Metab. 30:386-392.

10. Thompson, R. G., A. Rodriguez, A. Kowarski, and R. M. Blizzard. 1972. Growth hormone: metabolic clearance rates, integrated concentrations, and production rates in normal adults and the effects of prednisone. J. Clin. Invest. 51:3193-3199.

11. Gelato, M. C., E. Oldfield, D. L. Loriaux, and G. R. Merriam. 1990. Pulsatile growth hormone secretion in patients with acromegaly and normal men: the effects of growth hormone-releasing hormone infusion. J. Clin. Endocrinol. Metab. 71:585-590.

12. Roelfsema, F., H. De Boer, and M. Frölich. 1990. The influence of octreotide treatment on pulsatile growth hormone release in acromegaly. Clin. Endocrinol. (Oxf.) 33:297-306.

13. Riedel, M., T. Günther, A. von zur Mühlen, and G. Brabant. 1992. The pulsatile GH secretion in acromegaly: Hypothalamic or pituitary origin? Clin. Endocrinol. (Oxf.). 37:233-239.

14. Beckers, A., A. Stevenaert, J. M. Foidart, G. Hennen, and F. Frankenne. 1990. Placental and pituitary growth hormone secretion during pregnancy in acromegalic women. J. Clin. Endocrinol. Metab. 71:725-731.

15. Ho, P. J., R. D. Friberg, and A. L. Barkan. 1992. Regulation of pulsatile growth hormone secretion by fasting in normal subjects and patients with acromegaly. J. Clin. Endocrinol. Metab. 75:812-819.

16. Stewart, J. K., D. K. Clifton, D. J. Koerker, A. D. Rogol, T. Jaffe, and C. J. Goodner. 1985. Pulsatile release of growth hormone and prolactin from the primate pituitary in vitro. Endocrinology. 116:1-5.

17. Veldhuis, J. D., and M. L. Johnson. 1992. Deconvolution analysis of hormone data. Methods Enzymol. 210:539-575.

18. Pincus, S. M. 1991. Approximate entropy as a measure of system complexity. Proc. Natl. Acad. Sci. USA. 88:2297-2301.

19. Pincus, S. M., and D. L. Keefe. 1992. Quantification of hormone pulsatility via an approximate entropy algorithm. Am. J. Physiol. 262:E741-E754.
20. Faunt, L. M., and M. L. Johnson. 1992. Analysis of discrete, time-sampled data using Fourier series method. Methods Enzymol. 210:340-356.

21. Hartman, M. L., A. C. S. Faria, M. L. Vance, M. L. Johnson, M. O. Thorner, and J. D. Veldhuis. 1991. Temporal structure of in vivo growth hormone secretory events in humans. Am. J. Physiol. 260:E101-E110.

22. Hartman, M. L., J. D. Veldhuis, M. L. Johnson, M. M. Lee, K. G. M. M. Alberti, E. Samojlik, and M. O. Thorner. 1992. Augmented growth hormone (GH) secretory burst frequency and amplitude mediate enhanced GH secretion during a two day fast in normal men. J. Clin. Endocrinol. Metab. 74:757-765.

23. Furlanetto, R. W., and J. M. Marino. 1987. Radioimmunoassay of somatomedin-C/insulin-like growth factor I. Peptide Growth Factors Part A. Methods Enzymol. 146:216-227.

24. Ho, K. Y., J. D. Veldhuis, M. L. Johnson, R. Furlanetto, W. S. Evans, K. G. M. M. Alberti, and M. O. Thorner. 1988. Fasting enhances growth hormone secretion and amplifies the complex rhythms of growth hormone secretion in man. J. Clin. Invest. 81:968-975.

25. Felder, R. A., R. W. Holl, P. Martha, jr., G. Bauler, P. Hellman, M. R. Wills, and M. O. Thorner. 1989. Influence of matrix on concentrations of somatotropin measured in serum with commercial immunoradiometric assays. Clin. Chem. 35:1423-26.

26. Faria, A. C. S., J. D. Veldhuis, M. O. Thorner, and M. L. Vance. 1989. Half-time of endogenous growth hormone (GH) disappearance in normal man after stimulation of GH secretion by GH-releasing hormone and suppression with somatostatin. J. Clin. Endocrinol. Metab. 68:535-541.

27. Hindmarsh, P. C., D. R. Matthews, C. E. Brain, P. J. Pringle, L. Di Silvio, A. B. Kurtz, and C. G. D. Brook. 1989. The half-life of exogenous growth hormone after suppression of endogenous growth hormone with somatostatin. Clin. Endocrinol. (Oxf.) 30:443-450.

28. Veldhuis, J. D., and M. L. Johnson. 1988. A novel general biophysical model for simulating endocrine gland signaling. Am. J. Physiol. 255:E749-E759.

29. Pincus, S. M., I. M. Gladstone, and R. A. Ehrenkranz. 1991. A regularity statistic for medical data analysis. J. Clin. Monit. 7:335-345.

30. Pincus, S. M., T. R. Cummins, and G. G. Haddad. 1993. Heart rate control in normal and aborted SIDS infants. Am. J. Physiol. 264:R638-R646.

31. Pincus, S. M., and W. M. Huang. 1992. Approximate entropy: statistical properties and applications. Commun. Statist. Theory Meth. 21:3061-3077.

32. Bard, Y. 1974. Nonlinear Parameter Estimation. Academic Press, New York. 201.

33. Akaike, H. 1974. A new look at the statistical model identification. IEEE Trans. Autom. Control. AC-19:716-723.

34. Thomas, G. B., J. T. Cummins, H. Francis, A. W. Sudbury, P. I. McCloud, and I. J. Clarke. 1991. Effect of restricted feeding on the relationship between hypophysial portal concentrations of growth hormone (GH) - releasing factor and somatostatin, and jugular concentrations of $\mathrm{GH}$ in ovariectomized ewes. Endocrinology. 128:1151-1158.

35. Hartman, M. L., P. E. Clayton, M. L. Johnson, A. C. Celniker, A. J. Perlman, K. G. M. M. Alberti, and M. O. Thorner. 1993. A low-dose euglycemic infusion of recombinant human insulin-like growth factor I rapidly suppresses fasting-enhanced pulsatile growth hormone secretion in humans. J. Clin. Invest. 91:2453-2462.

36. Gelato, M. C., G. R. Merriam, M. L. Vance, J. A. Goldman, C. Webb, W. S., Evans, J. Rock, E. H. Oldfield, M. E. Molitch, J. Rivier, W. Vale, S. Reichlin, L. A. Frohman, D. L. Loriaux, and M. O. Thorner. 1985. Effects of growth hormone-releasing factor on growth hormone secretion in acromegaly. $J$. Clin. Endocrinol. Metab. 60:251-257.

37. Iranmanesh, A., B. Grisso, and J. D. Veldhuis. 1994. Low basal and persistent pulsatile growth hormone secretion are revealed in normal and hyposomatotropic men studied with a new ultrasensitive chemiluminescence assay. $J$. Clin. Endocrinol. Metab. 78:526-535.

38. Ralph, M. R., R. G. Foster, F. C. Davis, and M. Menaker. 1990. Transplanted suprachiasmatic nucleus determines circadian period. Science (Wash. DC). 247:975-978.

39. Herman, V., J. Fagin, R. Gonsky, K. Dovacs, and S. Melmed. 1990. Clona origin of pituitary adenomas. J. Clin. Endocrinol. Metab. 71:1427-1433.

40. Adams, E. F., M. Buchfelder, A. Hüttner, S. Moreth, and R. Fahlbusch. 1993. Recent advances in the molecular biology of growth-hormone secreting human pituitary tumours. Exp. Clin. Endocrinol. 101:12-16.

41. Landis, C. A., S. B. Masters, A. Spada, A. M. Pace, H. R. Bourne, and L. Vallar. 1989. GTPase inhibiting mutations activate the $\alpha$ chain of $G_{\mathbf{s}}$ and stimulate adenylyl cyclase in human pituitary tumours. Nature (Lond.). 340:692696.

42. Lyons, J., C. A. Landis, G. Harsh, L. Vallar, K. Grünewald, H. Feichtinger, Q-Y Duh, O. H. Clark, E. Kawasaki, H. R. Bourne, and F. McCormick. 1990. Two $G$ protein oncogenes in human endocrine tumors. Science (Wash. DC). 249:655-659.

43. Landis, C. A., G. Harsh, J. Lyons, R. L. Davis, R. McCormick, and H. R. Bourne. 1990. Clinical characteristics of acromegalic patients whose pituitary tumors contain mutant $\mathrm{G}_{\mathrm{s}}$ protein. J. Clin. Endocrinol. Metab. 71:1416-1420. 
44. Spada, A., M. Arosio, D. Bochicchio, N. Bazzoni, L. Vallar, M. Bassetti, and G. Faglia. 1990. Clinical, biochemical, and morphological correlates in patients bearing growth hormone-secreting pituitary tumors with or without constitutively active adenylyl cyclase. J. Clin. Endocrinol. Metab. 71:1421-1426.

45. Drews, R. T., R. A. Gravel, and R. Collu. 1992. Identification of $G$ protein $\alpha$ subunit mutations in human growth hormone (GH) - and GH/prolactin-secreting pituitary tumors by single-strand conformation polymorphism (SSCP) analysis. Mol. Cell. Endocrinol. 87:125-129.

46. Vallar, L., A. Spada, and G. Giannattasio. 1987. Altered $G_{3}$ and adenylate cyclase activity in human GH-secreting pituitary adenomas. Nature (Lond.). 330:566-568.

47. U, H. S., P. Kelley, and W. H. Lee. 1988. Abnormalities of the human growth hormone gene and protooncogenes in some human pituitary adenomas. Mol. Endocrinol. 2:85-89.

48. Asa, S. L., K. Kovacs, L. Stefaneanu, E. Horvath, N. Billestrup, C. Gonzalez-Manchon, and W. Vale. 1992. Pituitary adenomas in mice transgenic for growth hormone-releasing hormone. Endocrinology. 131:2083-2089.

49. Zimmerman, D., W. F. Young, Jr., M. J. Ebersold, B. W. Scheithauer, K. Kovacs, E. Horvath, M. D. Whitaker, N. L. Eberhardt, T. R. Downs, and L. A. Frohman. 1993. Congenital gigantism due to growth hormone-releasing hormone excess and pituitary hyperplasia with adenomatous transformation. J. Clin. Endocrinol. Metab. 76:216-222.

50. Asa, S. L., B. W. Scheithauer, J. M. Bilbao, E. Horvath, N. Ryan, K. Kovacs, R. V. Randall, E. R. Laws, Jr., W. Singer, J. A. Linfoot, M. O. Thorner, and W. Vale. 1984. A case for hypothalamic acromegaly: a clinicopathological study of six patients with hypothalamic gangliocytomas producing growth hormone-releasing factor. J. Clin. Endocrinol. Metab. 58:796-803.

51. Lamberts, S. W. J., T. Verleun, and R. Oosterom. 1984. The interrelationship between the effects of somatostatin and human pancreatic growth hormone- releasing factor on growth hormone release by cultured pituitary tumor cells from patients with acromegaly. J. Clin. Endocrinol. Metab. 58:250-254.

52. Hofland, L. J., P. M. Van Koetsveld, C. C. J. Van Vroonhoven, S. Z. Stefanko, and S. W. J. Lamberts. 1989. Heterogeneity of growth hormone (GH) release by individual pituitary adenoma cells from acromegalic patients, as determined by the reverse hemolytic plaque assay: effects of SMS 201-995, GHreleasing hormone and thyrotropin-releasing hormone. J. Clin. Endocrinol. Metab. 68:613-620.

53. Holl, R. W., M. O. Thorner, G. L. Mandell, J. A. Sullivan, Y. N. Sinha, and D. A. Leong. 1988. Spontaneous oscillations of intracellular calcium and growth hormone secretion. J. Biol. Chem. 263:9682-9685.

54. Dufy-Barbe, L., L. Bresson, P. Sartor, M-F Odessa, and B. Dufy. 1992. Calcium homeostasis in growth hormone (GH)-secreting adenoma cells: effect of GH-releasing factor. Endocrinology. 131:1436-1444.

55. Jaffe, C. A., R. D. Friberg, and A. L. Barkan. 1993. Suppression of growth hormone (GH) secretion by a selective GH-releasing hormone (GHRH) antagonist. Direct evidence for involvement of endogenous GHRH in the generation of GH pulses. J. Clin. Invest. 92:695-701.

56. Ho, P. J., R. D. Friberg, J. Lyons, H. R. Bourne, and A. L. Barkan 1991. Clinical, morphologic and secretory characteristics of human GH-producing pituitary tumors with or without a gsp mutation. Clin. Res. 39:324A. (Abstr.)

57. Weinstein, L. S., A. Shenker, P. V. Gejman, M. J. Merino, E. Friendman, and A. M. Speigel. 1991. Activating mutations of the stimulatory $G$ protein in the McCune-Albright syndrome. N. Engl. J. Med. 325:1688-1695.

58. Kovacs, K., E. Horvath, M. O. Thorner, and A. D. Rogol. 1984. Mammosomatotroph hyperplasia associated with acromegaly and hyperprolactinemia in a patient with the McCune-Albright syndrome. A histologic, immunocytologic and ultrastructural study of the surgically-removed adenohypophysis. Virchows Arch. A. Pathol. Anat. 403:77-86. 